\title{
High density lipoprotein cholesterol (HDL-C) analysis in leprosy patients
}

\author{
V SRITHARAN, $*$ V P BHARADWAJ, $\dagger$ \\ $\mathrm{K}$ VENKATESAN, $\uparrow \mathrm{B} \mathrm{K}$ GIRDHAR $\uparrow \& \mathrm{~K}$ V DESIKAN $\dagger$ \\ * Department of Biochemistry, University College of Medical \\ Sciences, New Delhi-110029, India; $\dagger$ Central J ALM A Institute for \\ Leprosy, Taj Ganj, Agra-282001, India
}

Accepted for publication 18 August 1983

\begin{abstract}
Summary A study was undertaken with a n aim to find out the levels of circulating high density lipoprotein (HDL) cholesterol and ratio of this fraction to total blood cholesterol in lepromatous leprosy patients before and after drug therapy. The healthy contacts of these patients were considered as control subjects of the study. The subjects were distributed in three groups on the basis of their age. HDL-cholesterol to total cholesterol ratio was significantly raised in both treated and untreated patients in all three groups compared to the healthy controls. The data may explain the low risk of myocardial infarction due to atherosclerosis in leprosy patients.
\end{abstract}

\section{Introduction}

A strong inverse relation exists between plasma levels of high density lipoprotein (HDL) and mortality from coronary heart disease. The role of HDL as a risk-preventing factor and the importance of this cholesterol-carrying protein in patients who are likely to develop risk of coronary heart disease have been of great importance to both clinicians and biochemists. High levels of serum HDL-C are associated with a low incidence of the complications of atherosclerosis, whereas low levels are associated with an increased incidence. Various factors are known to influence the plasma levels of HDL-C. ${ }^{7-13}$ There seems to be a direct correlation between the low-density lipoprotein cholesterol (LDL-C) and coronary heart disease (CHD) but it is said to be less consistent compared to inverse correlation existing between HDL-C and CHD. ${ }^{4}$ There is definitive alteration in the lipid metabolism of leprosy patients as has been shown by many workers. ${ }^{14-21}$ Atherosclerosis and CHD appear to be very uncommon in leprosy patients. ${ }^{26-28}$ Although there have been many reports regarding general serum 
lipid status of leprosy patients, no one has so far attempted to find out the HDL-C which can offer a better explanation of the hitherto unexplained difference in CHD prevalence and incident rates in leprosy patients. The present study is the continuation of our earlier work..$^{20}$

\section{Materials and methods}

Ninety-three cases were included in this study. All were male and none of them had any previous clinical record of cardiovascular involvement. Factors known to affect lipid metabolism like alcohol, smoking, diet, etc., were carefully taken into account when selecting the cases. They were clinically diagnosed and divided into three groups. Group I. Twenty-five cases of untreated lepromatous leprosy, Group II had 46 cases of treated lepromatous leprosy, and Group III consisted of 22 cases of healthy contacts of lepromatous leprosy. All of them belonged to the same socio-economic status. Each group was subdivided into three age groups: (a) 30-39 years, (b) 40-49 years, and (c) 50-60 years. Treatment included administration of dapsone, clofazimine or rifampicin but none of the patients were given steroids or any other drug known to affect lipid metabolism.

Fasting blood samples were collected and fresh sera were used for analysis. Separation of HDL fraction and estimation of cholesterol in that fraction were carried out according to the method of Vikari. ${ }^{22}$ Twelve per cent (w/v) PEG-6000 was used as a precipitating agent. But instead of adding equal volume of the precipitating agent to the serum, double the volume was added, i.e. to one part of serum two parts of $12 \%$ PEG-6000 were added in order to get maximum precipitation of LDL-fraction. Total cholesterol was estimated by the method of Zak et al. ${ }^{23}$

\section{Results and discussion}

It was found that the HDL-C was significantly higher in group Ic compared to control group III $(P<0 \cdot 05)$, even though all other age groups tended to show a marginal increase in values. After treatment, again the 50-60 years group (IIc) presented significantly higher value of HDL-C $(P<0 \cdot 05)$.

After treatment, in group IIc there was an increase in HDL-C compared to that of group IIIc but there was not any marked change from the untreated patients of the same age group. The statistical analysis and comparison of groups I and II show that no importance could be attributed to the effect of therapy per se.

The values of the ratio of HDL-C to total cholesterol were significantly higher in all subgroups of groups I and II compared to the corresponding results of control group III. The results of the present study are given in Table 1 . 
Table 1. High density lipoprotein cholesterol analysis in leprosy patients and healthy controls

\begin{tabular}{lllll} 
Clinical condition & \multicolumn{1}{c}{$\begin{array}{c}\text { Age group } \\
\text { (all males) }\end{array}$} & $\begin{array}{c}\text { Serum total } \\
\text { cholesterol } \\
\text { (TC) } \mathrm{mg} \%\end{array}$ & $\begin{array}{c}\text { HDL-cholesterol } \\
\text { (HDL-C) } \mathrm{mg}^{\dagger}{ }^{\dagger}\end{array}$ & HDL-C/TC \\
\hline $\begin{array}{l}1 \text { Untreated } \\
\text { lepromatous }\end{array}$ & (a) $30-39(14)$ & $113 \pm 22 \cdot 8$ & $29 \cdot 48 \pm 10 \cdot 59^{*}$ & $0 \cdot 258 \pm 0 \cdot 061(P<0 \cdot 05)$ \\
leprosy & (b) $40-49(7)$ & $120 \pm 18 \cdot 6$ & $24 \cdot 11 \pm 4 \cdot 87^{*}$ & $0 \cdot 203 \pm 0 \cdot 007(P<0 \cdot 05)$ \\
2 Treated & (a) $30-60(4)$ & $138 \pm 16 \cdot 4$ & $60 \cdot 25 \pm 4 \cdot 92(P<0 \cdot 05)$ & $0 \cdot 436 \pm 0 \cdot 014(P<0 \cdot 02)$ \\
lepromatous & (b) $40-49(12)$ & $118 \pm 21 \cdot 8$ & $30 \cdot 60 \pm 7 \cdot 00^{*}$ & $0 \cdot 250 \pm 0 \cdot 014(P<0 \cdot 05)$ \\
leprosy & (c) $50-60(6)$ & $150 \pm 17 \cdot 8$ & $68 \cdot 78 \pm 6 \cdot 64(P<0 \cdot 05)$ & $0 \cdot 346 \pm 0 \cdot 006(P<0 \cdot 02)$ \\
3 Healthy & (a) $30-39(11)$ & $140 \pm 16 \cdot 8$ & $23 \cdot 46 \pm 3 \cdot 38$ & $0 \cdot 177 \pm 0 \cdot 014$ \\
contacts of & (b) $40-49(4)$ & $150 \pm 17 \cdot 5$ & $20 \cdot 06 \pm 9 \cdot 16$ & $0 \cdot 123 \pm 0 \cdot 044$ \\
lepromatous & (c) $50-60(7)$ & $158 \pm 24 \cdot 8$ & $40 \cdot 62 \pm 3 \cdot 95$ & $0 \cdot 255 \pm 0 \cdot 015$ \\
leprosy & & & & \\
(control cases) & & & & \\
\hline
\end{tabular}

* Statistically not significant.

$\dagger$ Standard deviation of the mean values. Numbers in parentheses indicate number of cases studied.

It is well known that compared to a normal population the prevalence of CHD due to atherosclerosis is much less in leprosy patients. ${ }^{26,28}$ This might be due to their favourable HDL-C/Total cholesterol ratio and higher HDL-C levels than the controls as of our study. Heart, large blood vessels and gall bladder are somehow not affected by leprosy. There are no references in the literature regarding the involvement of heart and the formation of atheroma in big vessels. ${ }^{26,28}$ Documented reports for the involvement of cardiovascular system are (a) specific endocarditis due to rapidly growing chromogenic mycobacteria, and (b) specific allergic vasculitis and phlebitis, both cited. ${ }^{28}$ However, peripheral arteries and veins reveal sclerosis. Two cases of definitive cardiac involvement in lepromatous leprosy have recently been presented ${ }^{28}$ where again the biochemical findings are not complete and that no data are presented on the cholesterol and lipoprotein levels. They speculated that leprosy might have affected the coronary vessels giving rise to CHD. Recent studies have shown that HDL is an independent risk-lowering factor. ${ }^{9}{ }^{24}$ Higher levels of HDL-C may be protective against the development of atherosclerosis and hence CHD. The following explanations ${ }^{6,25}$ have been provided to explain the role of HDL-C as a protective factor.

(a) Higher concentrations of HDL-C prevent deposition of cholesterol from LDL by blocking the latter's receptors and hence its uptake by endothelial cells.

(b) HDL provides a carrier to transport cholesterol from peripheral tissues to the liver where it is catabolized and excreted. 
(c) HDL prevents the accumulation of cholesterol esters inside cells, especially those of the reticulo-endothelial system which phagocytose red blood cells and other dying cells whose membranes contain cholesterol.

So far as our understanding goes, there have been no reports on the effects of dapsone, clofazimine or rifampicin affecting the lipid metabolism in leprosy patients. Our present study has not shown any significant change in HDL-C levels after the patients have commenced taking these drugs. Even though group Ic showed higher values for HDL-C the number of cases we could investigate was only four and this very small number makes our interpretation difficult. More information can be obtained if a controlled study is carried out to find the effect of various anti-leprosy drugs on the lipid metabolism of the patient. It would be useful to carry out an indepth epidemiological study to compare the prevalence of CHD and the usefulness of HDL-C in leprosy patients.

\section{Acknowledgment}

The secretarial assistance of Miss Madhu Kapoor is gratefully acknowledged.

\section{References}

${ }^{1}$ Barboriak JK, Anderson AJ, Rimm AA, King JF. High-density lipoprotein cholesterol and coronary artery occlusion. Met Clin \& Exp, 1979; 26: 735.

2 Barr DP, Rues EM, Eder HA. Protein-lipid relationships in human plasma. II. In atherosclerosis and related conditions. Amer J Med, 1951; 11: 480.

${ }^{3}$ Berg K, Borresen AL, Dehlen G. Serum high density lipoprotein and atherosclerotic heart disease. Lancet, 1956; 1: 499.

${ }^{4}$ Castelli WP, Doyle JT, Gordon T, Harnes CG, Hjortland MC, Hulley SB, Kagan A, Zukel WT. High density lipoprotein cholesterol and other lipids in coronary heart disease. The co-operative lipoprotein phenotyping study. Circulation, 1977; 55: 767.

${ }^{5}$ Gordon T, Castelli WP, Hjortland MC, Kannel WB, Dawber TR. High density lipoprotein as a protective factor against coronary heart disease-Framinghan study. Am J Med, 1977; 62: 707.

${ }^{6}$ Miller, GT, Miller NE. Plasma high density lipoprotein concentration and development of ischaemic heart disease. Lancet, 1975; 1: 16.

7 Tall AR, Small DM. Plasma high density lipoproteins. New Engl J Med, 1978; 299: 1232.

${ }^{8}$ Enger SC, Herbjarnsen K, Krkissen J, Fretland A. High density lipoproteins and physical activity; the influence of physical exercise, age and smoking on HDL-cholesterol and HDL-total cholesterol ratio. Scand J Clin Lab Invest, 1977; 37: 252.

9 Hulley SB, Cohen R, Widdowson G. Plasma high density lipoprotein cholesterol level; influence of risk factors intervention. JAMA, 1977; 238: 2269.

${ }^{10}$ Sprits N, Nishkel NA. Effects of dietary fats on plasma lipids and lipoproteins, a hypothesis for the lipid lowering effect of unsaturated fatty acids. J Clin Invest, 1969; 48: 78.

1 Hartung CH, Foreyt JP, Mitchell RE, Vlasek I, Gotto AM, Jr. Relationship of diet on HDL-cholesterol on sedentary and active middle aged men. Circulation, 1978, 57 \& 58 (Suppl 2.) II-204 abstract. 
12 Hartung GH, Foreyt JP, Mitchell RE, Vlasek I, Gotto AM Jr. Relation of diet to HDL-cholesterol and middle aged marathon runners, joggers and inactive men, New Engl $J$ Med, 1980; 302: 357.

${ }^{13}$ Carlson LA, Mossfeldt F. Acute effects of prolonged heavy exercise on the concentration of plasma lipids and lipoproteins in man. Acta Physiol Scand, 1964; 62: 51.

${ }^{14}$ Chekerdemian M. Serum cholesterol levels in leprosy. Le prologica, 1960; 5: 69.

15 Gokhale SK, Godbole SH. Serum lipolytic enzyme activity and serum lipid partition in leprosy and tuberculosis. Ind J Med Res, 1957; 45: 327.

16 Kapoor KK, Gupta SC. Serum cholesterol and Alkaline Phosphatase in different types of leprosy. Lepr India, 1974; 46: 152.

${ }^{17}$ Kusaka T. Alteration in the lipid content of the blood and tissues in leprosy patients. La Lepro, 1958; 27: 228.

18 Misra UK, Venkitasubramanian TA. Serum lipids in leprosy by silicic acid column chromatography. Int J Lepr, 1964; 32: 248.

19 Ramu G, Nagarajan V. Serum lipids in lepromatous leprosy. Ind Med Gazette, 1966; VI: 28.

${ }^{20}$ Sritharan V, Venkatesan K, Bharadwaj VP, Ramu G. Serum lipid profile in leprosy. Lepr India, 1979; 51: 515.

${ }^{21}$ Venkatesan K, Bharadwaj VP. Sequential biochemical investigations in lepromatous leprosy. Lepr India, 1978; 50: 166.

22 Vikari J. Precipitation of plasma lipoproteins by PEG-6000 and its evaluation with electrophoresis and ultra centrifugation. Scand J Clin Lab Invest, 1976, 36: 265.

${ }^{23}$ Zak B, Kickennan RL, White EG, Burnet H, Chernery PG. Estimation of cholesterol by Kiliani's reaction. Amer J Clin Path, 1954; 24: 1307.

${ }^{24}$ Blum CB, Lavy RI, Shlomo Eisenberg, Hall M, Goebel RN, Berman M. High density lipoprotein metabolism in man. J Clin Invest, 1977; 60: 795.

${ }^{25}$ Carew TB, Koschinsky T, Hayos SB, Steinberg D. A mechanism by which high density lipoproteins may slow the atherogenic process. Lancet, 1976; 1: 1315.

${ }^{26}$ Desikan KV, Job CK. A review of post-mortem findings in 37 cases of lepromatous leprosy. Int $J$ Lepr, 1968; 36: 32.

${ }^{27}$ Kaur S, Wahi PL, Chakravarthy RN, Sodhi JS, Vadhwa MB, Khera AS. Peripheral vascular deficit in 'leprosy'. Int J Lepr, 1976; 44: 332.

${ }_{28}$ Mathur SN, Itigi A, Krishnaveni A, Rao PD, Congestive heart failure in two patients of lepromatous leprosy. Lepr India, 1976; 48: 75.

${ }^{29}$ Geracÿe et al ??? 